\title{
Aesthetic Rehabilitation of Maxillary Anterior Teeth with Implant Supported Fixed Partial Prosthesis
}

\author{
Dipak M Shinde ${ }^{1}$, Surekha R Godbole ${ }^{2}$, Mithilesh M Dhamande ${ }^{3}$, Anagha R Dafade ${ }^{4}$ \\ 1, 2, 3, 4 Department of Prosthodontics, Datta Meghe Institute of Medical Sciences, \\ Sharad Pawar Dental College \& Hospital, Sawangi, Wardha, Maharashtra, India.
}

\section{INTRODUCTION}

Aesthetic result is an essential factor for defining success in implant placement. Long term studies have shown high survival rates in single or multiple implant placement. But, in aesthetic areas of mouth, along with implant survival, aesthetic success of implant therapy is also an important factor. Many elements contribute to this "success" and can be evaluated objectively. These elements are healing capability of the individual, the conditions of soft and hard tissues present, and the provisional and final restorations. In this case report we have described the treatment plan, surgical and prosthetic procedure done to rehabilitate individuals with edentulous area in maxillary anterior region.

Traumatic injury or a congenital anomaly is the common reason of tooth loss in anterior region of jaws. Various options like Removable dental prostheses, conventional fixed partial dentures (FPDs), resin-bonded FPDs, implant supported prostheses are existing for the replacement of missing teeth in anterior region. ${ }^{1-3}$

The discomfiture produced by unstable dentures and a continuous effort to stabilize them have led many people to strive for implant supported restorations. These restorations are implant supported, which do not transmit load to denture bearing areas, thus it does not cause bone resorption related with tissue-borne prostheses. ${ }^{4}$ Studies have proven that long-term benefits can be provided to edentulous patients using implant supported restorations, achieved using diligent surgical skills and proper restoration. ${ }^{5}$ Implant supported FPD is an ideal treatment option, for replacing missing teeth of aesthetic areas of mouth in young adult with completed skeletal and dental growth. ${ }^{6}$

In this case report we have described the treatment plan, surgical and prosthetic procedure done to rehabilitate individuals with edentulous area in maxillary anterior region.

\section{PRESENTATION OF CASE}

A 35-year-old male patient presented to the Department of Prosthodontics, Crown \& Bridge and Implantology, with chief complaint of loss of upper front teeth 8 months back due to trauma. Detailed intra oral examination revealed missing teeth in 11,21 , 22 and 46 regions and coronal tooth structure loss with 12 (Figure 1)
Corresponding Author: Dr. Dipak M Shinde.

Department of Prosthodontics, Datta Meghe Institute of Medical Sciences, Sharad Pawar Dental College \& Hospital, Sawangi, Wardha, Maharashtra, India. E-mail: deep.shinde50@gmail.com

\section{DOI: $10.14260 /$ jemds $/ 2020 / 676$}

How to Cite This Article:

Shinde DM, Godbole SR, Dhamande MM, et al. Aesthetic rehabilitation of maxillary anterior teeth with implant supported fixed partial prosthesis. J Evolution Med Dent Sci 2020;9(41):3079-3081, $10.14260 /$ jemds/2020/676

Submission 30-04-2020,

Peer Review 04-09-2020,

Acceptance 11-09-2020,

Published 12-10-2020.

Copyright (C) 2020 Dipak M Shinde, et al. This is an open access article distributed under Creative Commons Attribution License [Attribution 4.0 International (CC $B Y 4.0)]$ 


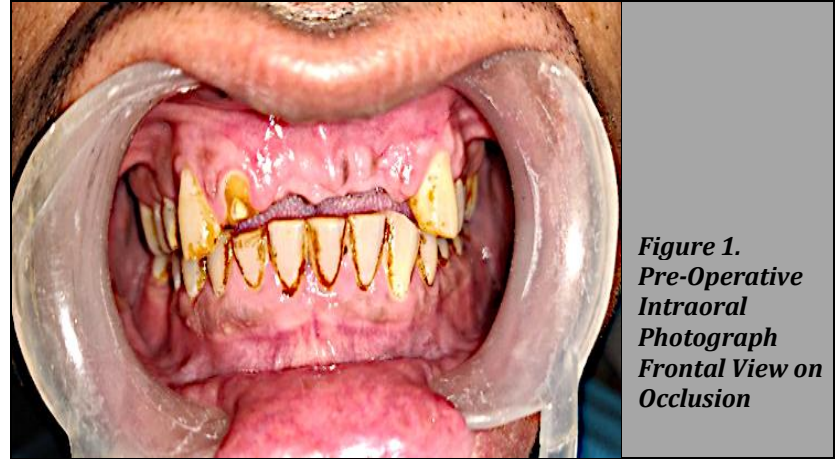

Patient's general periodontal condition of the remaining teeth was healthy, with pocket depths of less than $3 \mathrm{~mm}$ in all teeth. Study models were made and articulated. Radiographs (OPG \& CBCT) were taken to assess available bone height and width. The patient was presented with various treatment options. After discussing all treatment options, patient agreed for implant placement in missing teeth area. Diagnostic wax up was done to evaluate mesiodistal and apicoincisal space available for prosthetic rehabilitation.

After thorough diagnosis and treatment planning a twostage surgery for implant placement was planned for better osseointegration. Because of insufficient buccolingual width, endosseous implant measuring $3.5 \times 10 \mathrm{~mm}$ in dimension were selected for placement in 11 and 22 region. Cement retained prosthesis with 11,22 and post and core treatment was planned with 12 .

A parallel sided, threaded, implant was then placed under local anaesthesia. Primary stability was achieved at $35 \mathrm{~N}$ and cover screw was placed. [Figure 2]

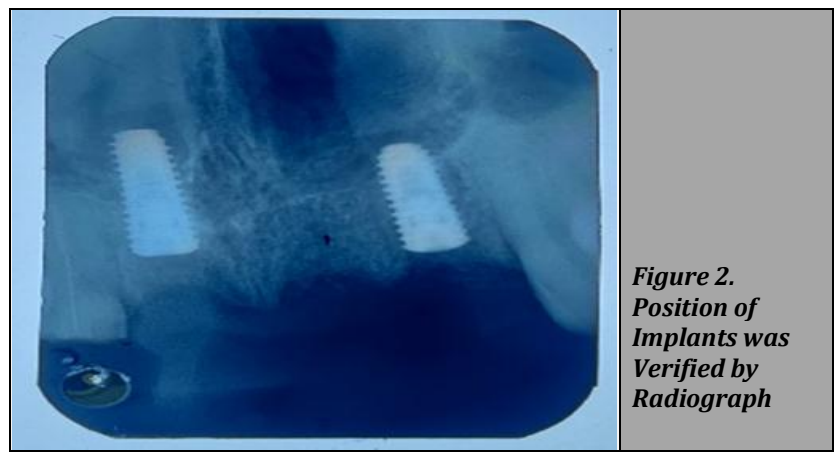

The patient was seen post-surgically after 1 week for follow up and no untoward sign or symptom was noted. Four months after implant placement cover screw was removed and the healing abutments were placed (Figure 3).

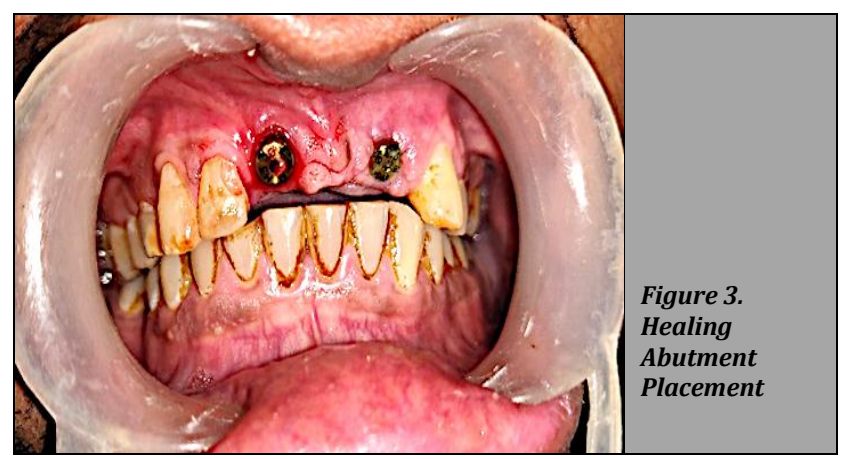

After 21 days once the gingival collar was formed, impression copings were placed and Poly Vinyl Siloxane closetray impression was made to capture the implant position. The impression copings were removed, and the healing abutments were replaced. Shade selection was done with shade guide and sent to the laboratory for the fabrication of cement retained metal ceramic fixed partial denture (FPD).

The final FPD was then tried in. The proximal contacts and occlusion were checked. In maximum intercuspation there was light contact with no contact in protrusive and lateral excursions. The crowns were then cemented using a luting cement. Oral hygiene instructions were given to patient and recalled after 3 months for regular check-up.
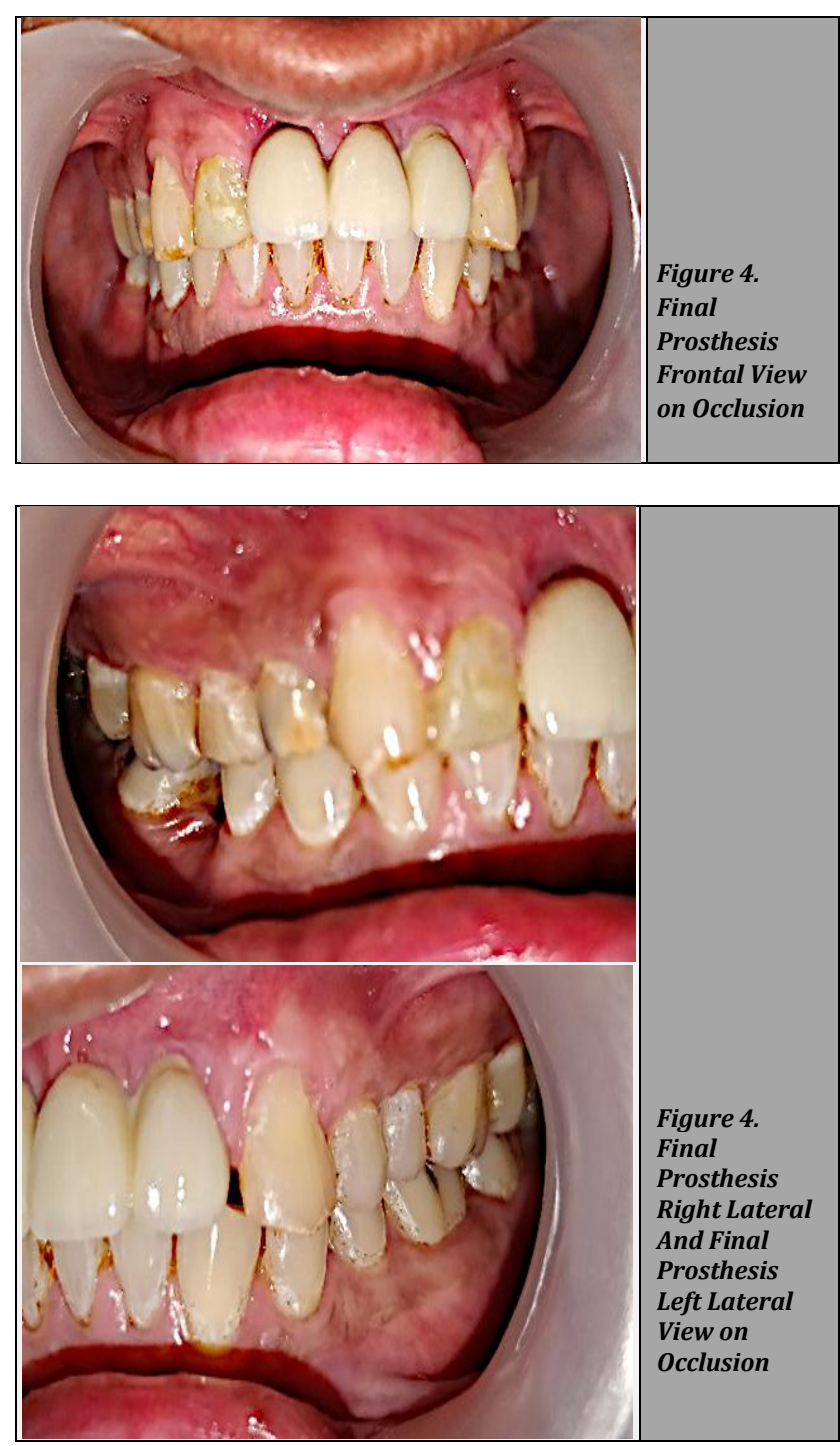

\section{DISCUSSION}

Patients think that dentists should preserve, produce, or improve a pleasing smile without harming the function of teeth but many patients take function of the teeth for granted. ${ }^{7}$ That is why accurate treatment planning, surgery, and prosthetic treatment are required for placing dental implants in the maxillary aesthetic area. A detailed understanding of anatomic, biologic, surgical, and prosthetic principles is 
necessary for successful aesthetic outcomes and satisfaction of patient for implant placement in the aesthetic areas of mouth. ${ }^{2}$ It is challenging to attain pleasant, indistinguishable prosthesis from neighbouring natural teeth in the aesthetic areas of mouth. During excursion the posterior teeth are sheltered by the anterior guidance, while at the time of centric occlusion the anterior teeth have only slight contact and are protected by the posterior teeth. It must be kept in mind that the anterior guidance of the implant prosthesis with anterior implants should be as shallow as possible. The steeper the anterior guidance, the greater are the anticipated forces on anterior implants. The rationale of mutually protected occlusion is that the forces are distributed to segments of the jaws with an overall decrease in force magnitudes. It must also be kept in mind that if anterior implants must disocclude the posterior teeth, two or more implants splinted together should help dissipate lateral forces whenever possible. ${ }^{8}$ Presence of screw on labial surface compromises the aesthetics of prosthetic rehabilitation so we planned for cement retained crown so as to provide better aesthetic results.

\section{CONCLUSIONS}

For missing teeth, implant supported fixed restorations are the best treatment options. The success of prosthetic rehabilitation depends upon pre-surgical analysis of position of implant placement, careful selection of materials used for prosthesis, design, and proper maintenance of prosthesis with a proper understanding of the individual's limitations \& expectations.

\section{REFERENCES}

[1] Jivraj S, Chee W. Treatment planning of implants in posterior quadrants. British Dent J 2006;201(1):13-23.

[2] Pan YH, Ramp LC, Lin CK, et al. Comparison of 7 luting protocols and their effect on the retention and marginal leakage of a cement-retained dental implant restoration. Int J Oral \& Maxillofacial Implants 2006;21(4):587-92.

[3] Atsu SS. A surgical guide for dental implant placement in edentulous posterior regions. J of Prosthetic Dent 2006;96(2):129-33.

[4] Agrawal N, Jain D, Gupta A. Prosthetic management of implants placed in anterior maxilla: a case report. IOSR Journal of Dental and Medical Sciences (IOSR-JDMS) 2018;17(9):64-7.

[5] Romanos GE, Nentwig GH. Immediate versus delayed functional loading of implants in the posterior mandible: A 2-year prospective clinical study of 12 consecutive cases. Int J of Perio \& Restorative Dent 2006;26(5):45969.

[6] Cornelini R, Cangini F, Covani U, et al. Immediate loading of implants with 3-unit fixed partial dentures: a 12-month clinical study. Int $J$ of Oral \& Maxiilofacial Implants 2006;21(6):914-8.

[7] Shinde DM, Godbole S, Borle AB, et al. Evaluation of correlation between facial midline and dental midline. International Journal of Current Research 2018;10(11):75667-9.

[8] Verma M, Nanda A, Sood A. Principles of occlusion in implant dentistry. J Int Clin Dent Res Organ 2015;7(3):2733.

Financial or Other Competing Interests: None. 